\title{
Radiation Preservation of Food
}

\author{
H. F. KRAYBILL, Ph.D.
}

GOON after World War II, studies sponsored $\infty$ by the Atomic Energy Commission disclosed that ionizing radiation could be used to preserve foods, and a new concept of food processing appeared. Preservation of food promises to be one of the most important peaceful uses of atomic energy.

Since food spoilage bacteria can be destroyed effectively by radiation with only a small rise in temperature, not more than $10^{\circ} \mathrm{C}$., and with remarkable speed, it is conceivable that irradiated foods can be made to surpass in flavor and texture foods preserved by other methods. Current research, sponsored largely by the Department of the Army, is directed toward this goal, as well as the demonstration of safety and nutritional adequacy.

Although many problems regarding the quality of certain irradiated foods remain to be solved, radiation treatment presently offers sereral interesting possibilities for increasing the supply of perishable food and safeguarding health. At levels much lower than the 2 or 3 million rep (roentgens equivalent physical) necessary for sterilization, radiation inhibits sprouting of potatoes $(10,000-30,000 \mathrm{rep})$, destroys trichina in pork $(30,000$ rep $)$, increases the keeping quality of perishable foods under refrigeration $(50,000-100,000$ rep), and destroys insect infestation (50,000-100,000 rep).

Either gamma or electron sources are used for radiation preservation of food. Mixed fis-

Dr. Kraybill is chief of the chemistry division, Army Medical Nutrition Laboratory, Fitzsimons Army Hospital, Denver, Colo. This article is based on a paper he presented at Pennsylvania's Fifth Annual Health Conference, held August 21, 1956, at Pennsylvania State University, University Park. sion products (spent fuel rods from nuclear reactors) and cobalt- 60 are the sources of gamma rays. Resonant transformers, Van de Graaff generators, and linear accelerators are the electron sources. Penetration of radiation from a gamma source is greater than that from an electron source, but a gamma source has the disadvantage of requiring continuous shielding. An electron source can be turned off and on.

Since pasteurization or sterilization of food requires rather high levels of radiation, higher than the level required for lethal effects against mammals and insects but lower than that for viruses and enzymes (fig. 1 ), it might be anticipated that rupture of chemical bonds would occur during processing. This has been found to be true. The molecular alteration in fat, protein, and carbohydrate in food produces certain noticeable changes in odor, color, fla vor, and texture (1). The effect of radiation on meat, which has been studied extensively, may be summarized as follows:

- Protein change: Increase in creatinine.

- Production of sulfur compounds: Hydrogen sulfide and mercaptans produced at 70,000 rep.

- Pigmental changes: Oxymyoglobin and metmyoglobin formed.

- Enzyme inactivation: Proteinases inactivated at $1.6 \times 10^{6}$ rep.

Much of the current research work is concentrated on improvement of texture and flavor in an effort to increase acceptability of irradiated food. Foods sensitive to radiation undergo changes in sulfur-containing compounds, proteins, and unsaturated fatty acids as a result of interactions with free radicals during irradiation. One method of counteracting these effects would be the introduction of com- 


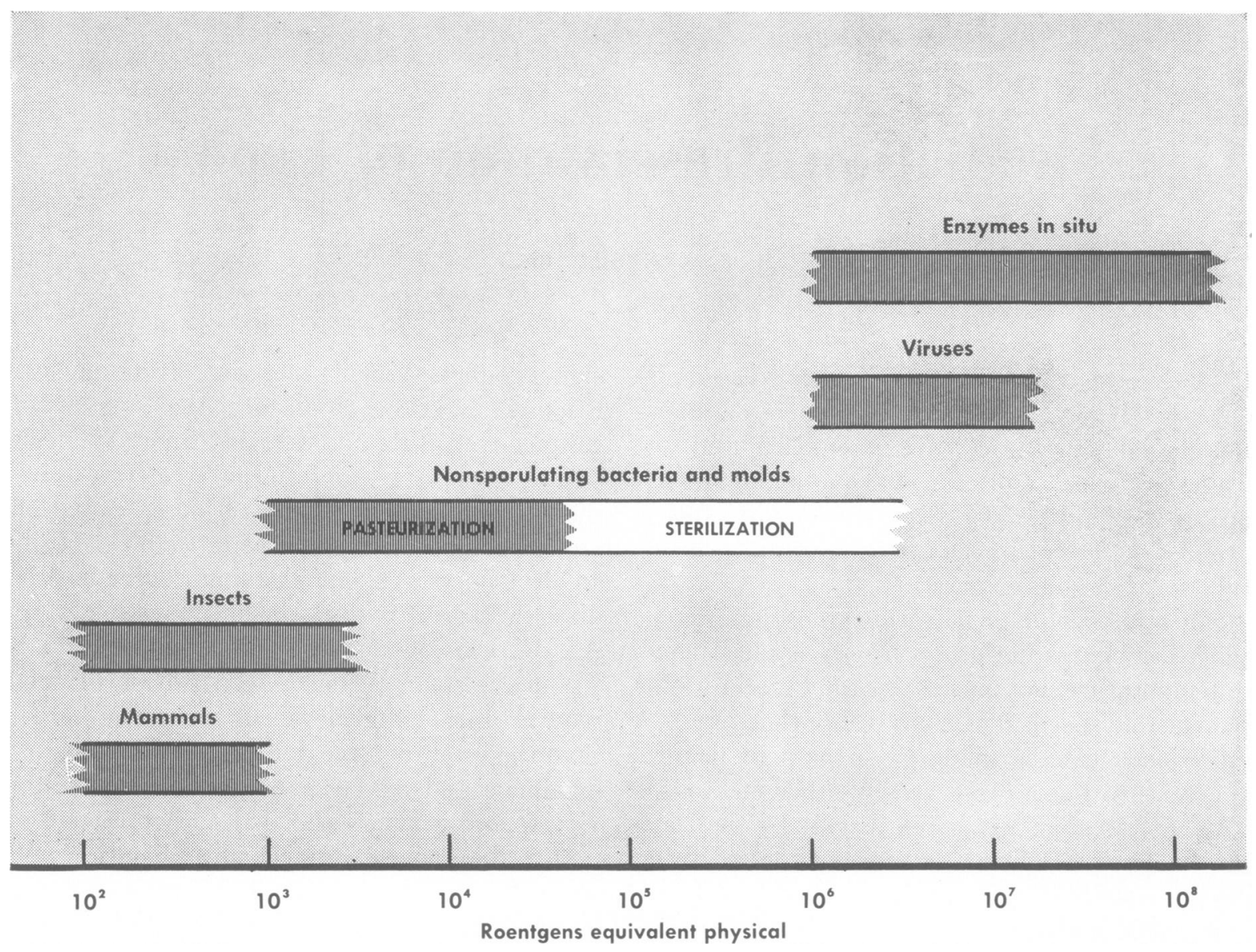

pounds that would serve as free radical acceptors. Such compounds, of course, must be acceptable as chemical additives. Other possibilities include packing the food under an inert gas atmosphere (nitrogen or helium, for example), prestoring the food to reduce the available oxygen, blanching prior to irradiation, and vacuum packing.

Since alteration in chemical structure is induced by radiation, it is possible that toxic degradation products may be produced through transformation of the macronutrients (fat, carbohydrate, and protein) and the micronutrients (vitamins) in the foodstuff. Assuming that radiation processing is technologically successful and economically feasible, it is likely that some day a significant proportion of man's diet will consist of irradiated food. It must be demonstrated, therefore, that foods treated with radiation are nontoxic to humans and that they are at least equal in nu- tritive value to foods preserved by canning or dehydration.

An excellent procedure for evaluating the wholesomeness of radiation-sterilized food has been described by Lehman and Laug (2). They suggest that studies on wholesomeness be directed along two major lines: potential toxicity and nutritional adequacy. Absence of induced radioactivity, carcinogenicity, and antigenicity must be established through extensive toxicity testing. Chemical and physical examination of the food prior to animal studies may provide important information for design of the toxicological study. For disclosing toxic effects, it is standard practice to challenge an animal with a relative excess of the test substance. For determining nutritional adequacy, the challenge should be made by reducing the vitamin supplement added to the basal ration to a level at which nutrient inadequacy would be intensified. 
Since the various species of animals, and even strains of the same species, frequently differ in sensitivity, a number of different species, such as the rat, the mouse, the dog, the monkey, and the chicken, should be included in the testing program. As radiation-induced changes in food are extremely subtle, the usual gross observations of growth, reproduction, and food consumption may not adequately describe toxic or harmful effects. It is desirable to include in the experiments a measure of cellular metabolism as a supplement to the gross observations. This can best be accomplished through application of enzyme analyses of tissues of the animals on the experimental diets.

Since March 1954 the Office of the Surgeon General, Department of the Army, has sponsored, through contracts with various institutions, a broad research program relating to wholesomeness of irradiated food, as outlined (see inset). Working closely with the Office of the Surgeon General in directing this program is the Food and Drug Administration, Department of Health, Education, and Welfare.

\section{Induced Radioactivity}

In first considering the possibilities of preserving food by means of radiation, it was assumed that the process would not induce radioactivity in the food, since gamma and electron sources are used and a neutron flux is not involved. One of the few direct studies of this question supports this assumption: No detectable amount of radioactivity was found in 24 common food elements that had been irradiated with a 1,000-curie cobalt-60 source (3).

Investigators are currently considering the possibility that accelerated electrons with beam energies greater than $10 \mathrm{Mev}$. might induce measurable amounts of radioactivity. Radiation preservation, however, is accomplished with beam energies far below this level. Also, Peterson and associates (4) noted that, following a nuclear explosion, food in unbroken containers at a distance of 1,700 feet from ground zero would be safe to eat. Induced radioactivity apparently is no problem in radiation processing of foods, provided no source of neutrons is present.

\section{Toxicity Studies}

One of the earliest studies of toxicity was reported by DaCosta and Levenson (5). These investigators found that a capacitronized synthetic ration fed to male and female weanling rats produced no deleterious effects on growth. However, there was impairment in the fertility of the male and increased mortality in litters that they believed was due to destruction of vitamin E. These findings were later corroborated by Poling and associates at the Swift and Company Research Laboratories in studies of irradiated ground beef $(6)$. They found that male infertility and viability of the young were readily corrected by supplementation of the diet with vitamin $\mathrm{E}$.

Similar studies on irradiated butterfat $(y)$ and on irradiated dried whole eggs (unpublished report by B. E. Proctor and John T. R. Nickerson of the Massachusetts Institute of Technology) indicate that these products have a slight effect on growth rate but essentially no toxic effects.

A three-generation mouse-feeding study, in which a semisynthetic diet sterilized by steam

\section{Army Wholesomeness Studies}

Short-term feeding (8 weeks). Army Medical Nutrition Laboratory and the University of Colorado: rat and man; Wisconsin Alumni Research Foundation: rat.

Longevity, reproduction, and lactation. Agricultural and Mechanical College of Texas: rat and chicken; University of Michigan : rat and chicken; Oregon State College: rat; Cornell University: dog; Columbia University: rat; Johns Hopkins University: rat; University of Illinois: rat and dog.

Nutritional adequacy. University of Illinois (protein) : rat; University of California at Los Angeles (fat): rat; Alabama Polytechnic Institute (vitamins) : rat.

Digestibility. University of Rochester: dog. Carcinogenicity. Wisconsin A l u m n i Research Foundation: rat and mouse.

Antigenicity of irradiated proteins. Army Medical Nutrition Laboratory and the University of Colorado: guinea pig. 
or cathode rays was compared with an unprocessed ration, revealed no differences in growth, general appearance, or reproduction. However, the mice raised on the irradiated diet exhibited some impairment in lactational performance $(8)$.

Short-term rat-feeding experiments with irradiated foods have been conducted by the Wisconsin Alumni Research Foundation, the Armour Research Foundation, and the Army Medical Nutrition Laboratory jointly with the University of Colorado to determine whether the foods are potentially toxic and to provide wholesomeness clearance for palatability testing by human subjects at the Quartermaster Food and Container Institute for the Armed Forces. Approximately 40 foods have received clearance by this procedure, and an additional 59 have been approved by extrapolation.

The irradiated foods that have received wholesomeness clearance have been fed for 30 days at levels of $35,65,80$, and 100 percent of the total calories in the diet to 10 human volunteers at the Army Medical Nutrition Laboratory. No untoward effects have been observed, and the volunteers have indicated equal acceptance of nonirradiated and irradiated foods (treated at 3 million rep) with only a few exceptions (fig. 2).

To evaluate the effects of a diet composed entirely of irradiated food, experiments in which rats receive such a diet are being conducted at the Army Medical Nutrition Laboratory. The diet is so composited as to provide proper levels of fat, carbohydrate, and protein. No adverse effects have developed through the first two generations.

Other longevity experiments with organ meats, pork, and a laboratory basal ration indicate that these irradiated foods are satisfactory for growth when fed at high levels to successive generations of rats. With other test species, such as the $\operatorname{dog}$ and the chicken, it has been demonstrated that, in comparison with a nonirradiated ration, irradiated rations support good growth, normal reproduction, and average food consumption.

Because of the possibility that irradiation may produce carcinogens in food, extensive investigations have been conducted by Teply and
Figure 2. Acceptability of typical irradiated and nonirradiated food: percentage distribution of ratings by test subjects.

\section{Peaches}

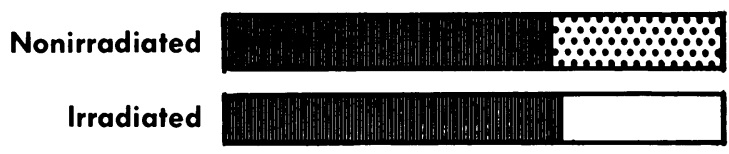

Strawberries

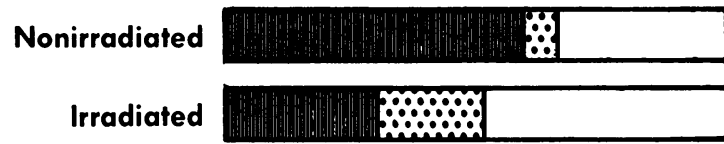

Bacon

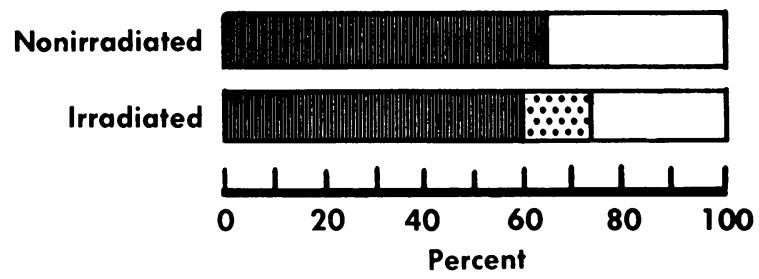

Like

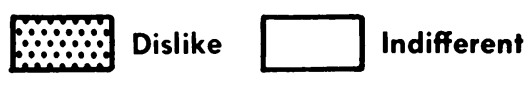

Kline (9) to determine whether irradiated sterols in extracts of egg, yeast, and pork will induce spontaneous tumor formation in rạts and mice when injected, fed, or painted on the skin of the test animal. From their experiments to date, there is no clear evidence of the production of carcinogens by irradiation of the food materials under study.

\section{Nutritional Adequacy}

The nutritive quality of irradiated food is evaluated by measuring the biochemical effects of ionizing radiation on individual macronutrients and micronutrients, as well as by observation of effects on animals in feeding experiments. Irradiated foods are compared with unprocessed foods and with heat-sterilized foods.

Andrews and co-workers (10) have shown that fats having peroxide values of 100 or less are not harmful to rats, whereas higher levels of peroxides produced by irradiation or oxidation are toxic. However, foods sterilized at 3 million rep have peroxide numbers well below 100, usually in the range of 70 to 80 . 
The effect of gamma radiation on carbohydrate has been studied extensively by Johnson and Metta (11). They found no significant alteration in the physiological energy of carbohydrate.

An important criterion in the evaluation of protein quality is the biological value of protein. Johnson and Metta have determined the biological value of the proteins of beef, milk, peas, and lima beans irradiated at 3 million rep, as shown in the table (11). According to this study, radiation has virtually no effect on the biological value of beef protein. The biological value of milk protein is reduced about 16 percent by radiation, as compared with about 6 percent by heat. Experiments in which irradiated milk was supplemented with various amino acids indicate that radiation causes a loss of cystine in milk protein. The decreased biological value of irradiated pea protein is probably due to destruction of sulfur amino acids, whereas the biological value of lima bean protein, which was improved considerably by heat but only slightly by radiation, can be accounted for by the destructive effect of heat on trypsin inhibitor.

Effects of heat sterilization and radiation sterilization on biological value of meat, milk, lima beans, and pea proteins

\begin{tabular}{c|r|r|r}
\hline \multirow{2}{*}{ Food } & \multicolumn{3}{|c|}{ Biological value (percent) } \\
\cline { 2 - 4 } & Raw & $\begin{array}{c}\text { Heat ster- } \\
\text { ilized }\end{array}$ & $\begin{array}{c}\text { Radiation } \\
\text { sterilized }\end{array}$ \\
\hline Meat & 78 & & 79 \\
Milk & 90 & 84 & 74 \\
Peas . & 59 & 58 & 50 \\
Lima beans & 50 & 68 & 51 \\
\hline
\end{tabular}

${ }^{1}$ Biological value $=\frac{\text { nitrogen utilized }}{\text { nitrogen absorbed }} \times 100$.

Source: Reference 11.

'The fat soluble and water soluble vitamins are sensitive to ionizing radiations, some more so than others. Proctor and Goldblith (12) have made extensive studies on the effect of ionizing radiations on the $B$ vitamins. While ascorbic acid is radiosensitive, riboflavin and niacin are radioresistant in dilute solution. Niacin in solution has a protective effect on
Figure 3. Percentage destruction of vitamins in various foods sterilized by heat and by ionizing radiation.

Thiamine

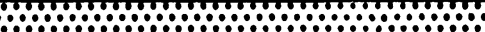

(III)

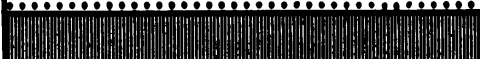

Riboflavin

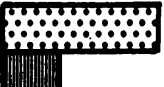

Pyridoxine

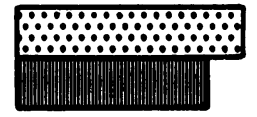

Niacin

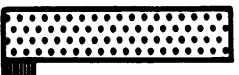

Folic acid

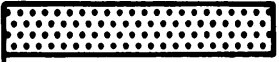

NONE

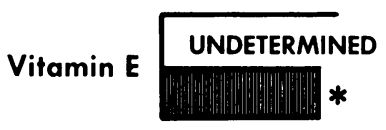

Vitamin A
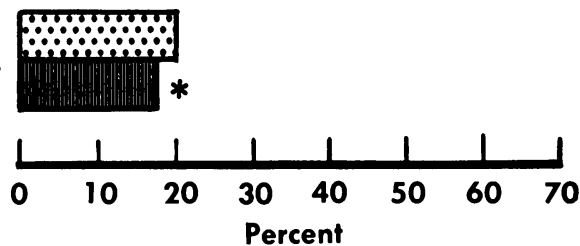

Heat sterilized

Radiation sterilized

* 80,000 roentgens per hour on dairy products

ascorbic acid. Foods act as natural protectors; for example, vitamin $\mathrm{B}_{12}$ in milk is decreased only 30 percent, whereas in aqueous solution 68 percent is destroyed. Although the destruction of vitamins due to radiation preservation may appear significant, most investigators feel that the vitamin loss is no greater than that experienced during thermal processing (fig. 3).

Gross effects from feeding irradiated foods to experimental animals have been measured by such indexes as growth, reproduction, and lactational performance. More recently, however, measurements of the activity of representative tissue enzymes involved in the metabolism of potential irradiation end products by the ani- 
mal provides more accurate information on the effect of feeding either irradiated or nonirradiated diets. At the Army Medical Nutrition Laboratory we have noted, for example, a higher activity of cytochrome oxidase in tissues from rats on irradiated diets than those maintained on nonirradiated diets. The difference was statistically significant at the 5 percent level. This would suggest that some interruption in lipid metabolism has been effected.

\section{Summary}

Treatment of foods with ionizing radiation promises revolutionary advances in food-preservation possibilities. There are still major technolcgical problems in regard to acceptability of certain foods processed with a radiation dose of 2 or 3 million rep. However, treatment at lower radiation levels, which produces such results as inhibition of sprouting of potatoes, destruction of trichina in pork, increase in the keeping quality of food under refrigeration, and destruction of insect infestation, is generally successful.

In experimental work undertaken thus far, radiation-sterilized foods have not been found toxic, nor has any evidence of carcinogenicity appeared. In animal feeding experiments with a wide variety of irradiated foods, reproduction and lactational performance in general are the same as for animals maintained on nonirradiated diets. One worker, using an irradiated synthetic diet, demonstrated slight impairment in lactational performance of mice, but this effect has not been induced in other animal species by feeding them irradiated foods. The nutritive value of these foods has been found to be equivalent to that for heatprocessed foods.

\section{REFERENCES}

(1) Pratt, G. B., and Ecklund, O. F.: Organoleptic studies of irradiated foods. Food Technol. $10: 496-499$, October 1956.

(2) Lehman, A. J., and Laug, E. P.: Evaluating the safety of radiation sterilized foods. Nucleonics 12 : 52-54, January 54 .

(3) Meinke, W. W.: Does irradiation induce radioactivity in food? Nucleonics 12: 37-39, October 1954 .

(4) Peterson, D. C., Webster, S. H., and Liljegren, E. J.: Activities induced in common foods by thermal neutron exposure. Nucleonics 10 : 33-36, January 1952.

(5) DaCosta, E., and Levenson, S. M. : Effect of diet exposed to capacitron irradiation on the growth and fertility of the albino rat. U. S. Army Medical Nutrition Laboratory Report No. 89. Chicago, 1951.

(6) Poling, C. E., Warner, W. D., Humburg, F. R., Reber, E. F., Urbain, W. M., and Rice, E. E. : Growth, reproduction, survival and histopathology of rats fed beef irradiated with electrons. Food Research 20: 193-214, May-June 1955.

$(\boldsymbol{\gamma})$ Kung, H. C., Gaden, E. L., and King, C. G.: Vitamins and enzymes in milk-Effect of gamma radiation on activity. I. Agric. Food Chem. 1: 142-144, Apr. 15, 1953.

(8) Luckey, T. D., Wagner, M., Reyniers, J. A., and Foster, F. I. : Nutritional adequacy of a semisynthetic diet sterilized by steam or cathode rays. Food Research 20: 180-18.5, MarchApril 1955.

(9) Teply, L. J., and Kline, B. E.: Wholesomeness and possible carcinogenicity of radiated foods. Federation Proc. 15: 927-929, September 1956.

(10) Andrews, J. S., Mead, J. F., and Griffith, W. H. : Toxicity of lipid peroxiles in the rat. Federation Proc. 15: 918-920, September 1956.

(11) Johnson, B. C., and Metta, V. C.: The effect of irradiation sterilization on nutritive value of protein and energy of food. Federation Proc. 15: 907-909, September 1956.

(12) Proctor, B. E., and Goldblith, S. A.: Effect of soft $\mathrm{X}$-ray on vitamins (niacin, riboflavin, and ascorbic acid). Nucleonics 5: 56-62, September 1949 . 